\title{
Delegated Activism and Disclosure
}

\author{
By \\ Amil Dasgupta \\ Konstantinos E. Zachariadis \\ THE PAUL WOOLLEY CENTRE \\ WORKING PAPER SERIES NO 27 \\ FINANCIAL MARKETS GROUP \\ DISCUSSION PAPER NO 689
}

July 2011

Amil Dasgupta is a Reader (Associate Professor) in the Department of Finance of the London School of Economics and a member of the Financial Markets Group. His research interests include information economics and game theory with applications to finance, the theory of delegated portfolio management and consequences for financial markets and the theory of financial crises. Konstantinos E. Zachariadis is a Lecturer in the Department of Finance at LSE, where he is also affiliated with the Financial Markets Group and the Paul Woolley Centre. His research interests lie in the areas of Market Design, Efficiency and Information Revelation in Markets, and Corporate Finance and Governance. He is also a Fulbright Fellow. Any opinions expressed here are those of the authors and not necessarily those of the FMG. The research findings reported in this paper are the result of the independent research of the authors and do not necessarily reflect the views of the LSE. 


\title{
Delegated Activism and Disclosure*
}

\author{
Amil Dasgupta ${ }^{\dagger} \quad$ Konstantinos E. Zachariadis ${ }^{\ddagger}$ \\ LSE and CEPR LSE
}

First version: August 2010

This version: June 2011

\begin{abstract}
Mutual funds hold large blocks of shares in many major corporations. Practitioners and regulators alike have been concerned that mutual funds use their proxy votes in a promanagement manner in order to garner lucrative pensions administration contracts, thus hindering shareholder value. Such concerns led the SEC to mandate the disclosure of mutual fund proxy votes starting in 2003. We present a simple model of mutual fund proxy voting in the presence of potential business ties. Our model generates clean predictions on how funds would vote both prior and subsequent to mandatory disclosure. We provide theoretical foundation for the limited activism of mutual funds and demonstrate that mandatory disclosure is not a panacea. We also show that the strategic interaction between multiple mutual fund blockholders of comparable size can generate counterintuitive non-monotone relationships with relevant empirical implications.
\end{abstract}

\section{Introduction}

In contrast to many other classes of asset managers, mutual funds, who manage indirect ownership of over $20 \%$ of US equity and hold sizeable blocks of $10 \%$ or more in many of the largest US corporations (Davis and Yoo (2003)), have been largely absent from public activism. ${ }^{1}$ Indeed, there has been widespread suspicion over a number of years that mutual funds actually oppose value-enhancing activism, voting in a pro-management manner in order

${ }^{*}$ We are grateful to Andres Almazan, Bernie Black, Daniel Ferreira, Dimitri Vayanos, and seminar audiences at Amsterdam, LSE, Warwick, and the WFA 2011 Annual Meeting for helpful comments. We thank the Paul Woolley Centre at the LSE for financial support.

${ }^{\dagger}$ a.dasgupta@lse.ac.uk

${ }^{\ddagger} \mathrm{k} . z a c h a r i a d i s @ l s e . a c . u k$

${ }^{1}$ There is some anecdotal evidence that some mutual funds have participated in the ousting of undesirable CEOs and directors whose compensation was not sufficiently linked to performance (see Gillan and Starks $(2007))$. 
to retain or garner lucrative pensions administration contracts from large corporations. Davis and Kim (2007) note, for example, that Fidelity assumes a much more activist stance in Europe where it has little role in pensions management while being much less activist in the US where a large part of its revenue comes from pensions administration. ${ }^{2}$ To put it in the words of the US Securities and Exchange Commission (SEC Release Nos 33-8188, 34-47304, IC-25922, page 3):

"...in some situations the interests of a mutual fund's shareholders may conflict with those of its investment adviser with respect to proxy voting. This may occur, for example, when a fund's adviser also manages or seeks to manage the retirement plan assets of a company whose securities are held by the fund. In these situations, a fund's adviser may have an incentive to support management recommendations to further its business interests..."

In response to these concerns, the SEC proposed in 2002 new regulations that would require that mutual funds disclose their proxy voting policies on shareholder proposals for portfolio firms, and to publish the votes actually cast. The degree of concern in the industry with regard to the potential for conflicted proxy voting by mutual funds is evidenced by the significant response received by the SEC during the consultation period, which was made up of several thousand letters of support for the proposed new rule from activist investors, labour union pensions funds, and other practitioners (SEC (2003)). In sharp contrast, the proposals were almost universally opposed by the mutual fund industry. Nevertheless, the SEC adopted the new rules (Rule 30b1-4 of the Investment Companies Act) effective in April 2003, making proxy voting policy disclosure and the recording of proxy votes by mutual funds mandatory.

Despite the polarization of opinion with regard to the new SEC regulations, little is known theoretically about why mutual fund activism was so limited prior to disclosure, and how mandatory disclosure is likely to affect the degree of activism. In this paper, we fill this gap by providing a simple game-theoretic model of mutual fund activism in the presence of potential business connections with portfolio firms. Our model features a dual-layered agency problem. Firms' executives may choose suboptimal projects to extract private benefits at the expense of shareholders. Shareholders bring forth proposals to reduce such private benefits. But the blockholders whose votes influence the fate of these proposals are mutual funds who compete with each other for lucrative pensions administration contracts which are at the giving of firms' executives.

\footnotetext{
${ }^{2}$ Another telling anecdote can be found in Black (1990), who describes an episode in which, Fidelity seemingly obtained Armstrong Inc's large pensions administration business from Vanguard by removing its opposition to a proposed controversial Pennsylvania law that enhanced the power of existing board to oppose takeovers.
} 
We provide theoretical foundations for the limited degree of shareholder activism by mutual funds prior to disclosure. Competition for lucrative pensions management fees leads funds to vote against proposals limiting managerial perks. Despite this endogenous paucity of pre-disclosure activism, we show that mandatory disclosure is not a panacea. This is so because, when the quality of a proposal is not verifiable, mandatory disclosure leads to a spillover effect: for a given proposal, funds vote identically across firms regardless of business ties. Indeed, our model identifies an important regularity that should arise in the postdisclosure data: mutual funds with more business connections should be less activist. Finally we show that, when firms have multiple mutual fund blockholders of comparable sizes, rich strategic interactions arise which lead to counterintuitive empirical predictions. For example, despite the pro-management stance of mutual fund blockholders arising from business ties, our model predicts potentially non-monotone relationships between the level of mutual fund holdings and the quality of corporate governance.

Many recent empirical studies have highlighted the perverse incentives in the proxy voting of funds arising from their role as pension funds managers. ${ }^{3}$ Davis and Kim (2007), Matvos and Ostrovsky (2010), and Cremers and Romano (2009) all report some departure from the optimal level of activism, from a firm's shareholders perspective, following disclosure. These findings raise the question of whether disclosure is a desirable regulation, even from the perspective of those in support of shareholder activism. Our paper provides a theoretical response to this implicit question: mandatory disclosure may or may not be desirable, depending on the degree to which shareholder proposals are actually value enhancing.

Importantly, the question is not merely of retrospective interest. In the wake of the recent financial crisis, there is a renewed interest in the role of institutional investors in corporate governance. Other countries may wish to emulate the US in implementing similar disclosure rules for mutual funds' proxy voting. For example, the influential Walker Review (Walker (2009), Recommendation 22, page 19) of the regulatory environment in the United Kingdom suggests that:

“...Voting powers should be exercised, fund managers and other institutional investors should disclose their voting record, and their policies in respect of voting should be described in statements on their websites or in other publicly accessible form..."

\footnotetext{
${ }^{3}$ Early empirical papers that studied the conflicts of interest due to business dealings, which may affect how institutional investors use their proxy votes, include Brickley, Lease, and Smith-Jr. (1988), and Pound (1988).
} 
The main actors in the model are two ex ante asymmetric investment funds, ${ }^{4}$ which invest on behalf of a large group of passive shareholders in a large number of ex ante symmetric firms, and a large number of small atomistic direct investors who also (directly) hold equity in these firms. ${ }^{5}$ We think of these two funds as representative of different types of funds, some of them with large blockholdings and others with small blockholdings. In particular, we dub one of the funds the "large fund" while the other fund is the "small fund". The large fund is characterized by significantly more voting power than the small fund. ${ }^{6}$

In addition to their role in investing in the firms on behalf of their investors, funds may act in the role of pensions administrators for the firms: for a fee, they collect and provide investment advisory and fund allocation services to the employees of the firm with regard to their pensions contributions. The direct shareholders of the firms can make efforts to reduce the agency rents that can be earned by the firms' managers by bringing forth proposals to reduce their private benefits from effort avoidance. Mutual funds vote on these proposals, along with small shareholders. Firms' managers observe voting and determine the recipient of the pensions administration contract. ${ }^{7}$ We list our main results below:

1. Limited activism: Both prior to and after disclosure, the large fund votes pro-management over a range of proposals, while the small fund always votes pro-management. This result provides theoretical grounding to a wide range of empirical and anecdotal observations about the limited degree to which mutual funds engage in anti-management voting. The result also provides a testable implication on the relative degree of activism of funds of different sizes.

2. Rewards for pro-management voting and bias for large funds as pension providers: Both prior to and after disclosure, firms' management hire the most pro-management fund,

\footnotetext{
${ }^{4}$ We interpret these as index funds of different sizes, because (as will become clear in the sequel) we do not consider the ex ante choice of share-holdings, which are implicitly dictated by index weights.

${ }^{5}$ The direct owners do not necessarily have to be small or uncoordinated. Indeed, they may be proxies for ownership by public pensions funds, labour union funds, activist "clubs" etc. The distinguishing feature of these investors is that they are purely interested in the value of the shares of the firm, and thus in reducing the rents that can be enjoyed by management.

${ }^{6}$ The degree of difference in voting power varies across different versions of the model. In the baseline model we assume that the large fund has the ability to unilaterally veto a proposal, i.e., it has full veto power, while the small fund has no veto power. In extensions, we consider cases where the large fund has only limited veto power.

${ }^{7}$ Throughout we assume that managers can observe the votes of funds prior to mandatory disclosure. This is a realistic assumption. First, many firms do not have confidential voting, and thus management sees votes as they come in. Even with confidential voting it is hard for a large blockholder to hide votes. Mutual funds usually own millions of shares and proxy solicitors (and hence also managers) are likely to be able to infer their votes. Furthermore, the conflict of interest alleged by so many parties would be absent if a fund could not signal to a firm's manager how it voted. It is worth noting that mutual funds were the only interest group which protested that disclosure might lead to firms penalizing them on how they vote.
} 
and amongst those (if the identity of the most pro-management fund is not unique) the largest one. Our result thus predicts that, larger mutual fund houses should end up with more business relationships. This seems to be supported by the evidence in, for example, Davis and Kim (2007).

3. The effect of disclosure on the overall level of activism by mutual funds is ambiguous: Our model implies that for very weak and very strong shareholder proposals (i.e., ones that add little or greatly to shareholder value) disclosure makes no difference whatsoever to mutual fund voting. However, for intermediate proposals, disclosure changes behaviour. For low intermediate value proposals, disclosure leads to less activism: funds that prior to disclosure voted pro-management on these proposals for only firms with which they had business dealings will now vote pro-management for all firms, regardless of whether they have business dealings with the firms. For high intermediate value proposals, disclosure leads to more activism: funds that prior to disclosure voted promanagement on these proposals for only firms with which they had business dealings will now vote against management for all firms, regardless of whether they have business dealings with the firms. Thus, whether disclosure increases or decreases the overall level of activism by mutual funds depends crucially on the distribution of shareholder proposals. In particular, there exist distributions of shareholder proposals for which disclosure reduces the overall level of activism by mutual funds. ${ }^{8}$

4. Post-disclosure, the larger the proportion of client relationships amongst the portfolio firms, the lower the level of overall activism: Post-disclosure funds calibrate their voting behaviour to the average firm that they encounter. The fund with more business relationships is likely to encounter more clients on average, and thus calibrates its activism at a lower level. This result provides a theoretical foundation for the main finding of Davis and Kim (2007).

5. The effect of funds of comparable sizes on the overall level of activism by mutual funds is ambiguous both pre- and post-disclosure: Our model implies that when no fund is a pivotal blockholder then the small fund is more active, compared to the baseline case where the large fund was pivotal. Furthermore if, in addition, funds are not pivotal even on aggregate then the large fund exercises less activism. The reason is that when the large blockholder does not have overwhelming voting power, he can vote in a pro-

\footnotetext{
${ }^{8}$ Our results are independent of the process that generates proposals. If shareholders and managers understand the effects of disclosure identified in this paper on the success of a given proposal, mandating disclosure may lead to a change in the distribution of proposals. Since proposals (and most voting outcomes) are publicly observed pre- and post-disclosure, the comparison of the distributions of proposals across these two periods represents an interesting potential empirical exercise.
} 
management manner and thus retain his pensions management contracts without ruling out the value improvement delivered to his portfolio should the shareholder proposal pass. This increased incentive of the large fund to vote with management has ambiguous effects on the overall probability of proposals passing. In particular, it is possible to make the probability of passage of beneficial proposals lower with lower mutual fund ownership. Hence there is not a uniform relationship between the total degree of ownership by mutual funds and the likelihood of shareholder proposals passing.

\subsection{Some related literature}

Our paper speaks directly to a small but growing set of recent empirical studies that have begun to investigate mutual fund activism in the aftermath of mandatory disclosure. In an important study, Davis and Kim (2007) use data on business connections and post-disclosure proxy voting by mutual funds to investigate patterns of behaviour. They find that the overall level of activism by mutual funds is decreasing in the amount of pensions management business that the fund is engaged in - a finding for which our model provides theoretical justification.

Matvos and Ostrovsky (2010) also study post-disclosure voting by mutual funds on firms' director elections and find that there is systematic heterogeneity in how funds vote upon ostensibly similar voting contests, heterogeneity which may be attributed to business ties between funds and portfolio firms. ${ }^{9}$

A recent paper that relates voting behaviour by mutual funds pre- and post-disclosure is by Cremers and Romano (2009). They confront the challenging task of inferring voting behaviour from outcomes prior to disclosure and consider the relationship between overall mutual fund ownership and voting outcomes pre- and post-disclosure. For management sponsored proposals to adopt or amend executive equity incentive compensation plans (EEIC), they find that there is some evidence to suggest that post-disclosure overall mutual fund support for management increased. We relate Cremers and Romano's findings to our theoretical results later in the paper.

Other aspects of how these business dealings may alter the incentives of mutual funds can be found in Cohen and Schmidt (2009) who show that mutual funds overweight client firms, and Duan, Hotchkiss, and Jiao (2011) who show that mutual funds may use valuable information they acquire by being pension managers. An important result in Duan, Hotchkiss, and Jiao (2011) that relates to our study is that the decision to hire mutual funds as pension managers is not driven by the portfolio management skills of the fund.

\footnotetext{
${ }^{9}$ Matvos and Ostrovsky (2010) also find strong peer effects, in the sense that ceteris paribus a fund will vote for a director if it believes others will vote for that director as well.
} 
Our paper has a family relationship with a number of well known papers that examine the role of large blockholders in monitoring firms (see, most famously, Grossman and Hart (1980) and Shleifer and Vishny (1986)). This literature has been concerned with costly monitoring, and incentives to monitor given the free-rider problem inherent in monitoring activities in the presence of many small shareholders. Admati, Pfleiderer, and Zechner (1994) show that monitoring can arise in equilibrium with endogenously selected blockholdings and the possibility of retrading in financial markets.

In contrast to these papers, we are not interested in costly monitoring or endogenous block-holdings. We are interested in an environment in which the blockholdings, as is the case for so many large mutual funds, are essentially determined by explicit or implicit indexing, or are of a size that cannot easily be retraded away. We consider a very specific form of monitoring, that of proxy voting. ${ }^{10}$ The benefits of being an active shareholder far exceed any costs (e.g., research for firm specific votes) and so "monitoring" in our setup is essentially free: the free-rider problem is not first order in our analysis. ${ }^{11}$ Moreover, it is exactly passive captive blockholders who have more value to salvage by becoming involved in the corporate governance of their portfolio firms.

We differ from this prior literature in another, deeper, sense. The theoretical literature discussed above treats large blockholders as, effectively, individual shareholders who happen to own large blocks. However, in reality, most blockholders are institutional traders, typically delegated portfolio managers. These traders are motivated by contractual incentives which give rise to agency problems. While a recent theoretical literature has started to consider the implications of agency problems in portfolio management for trading, prices, and other financial equilibrium quantities, there has been no attempt, to our knowledge, to examine the effect on corporate governance. ${ }^{12}$ Our paper represents a first step to begin to fill that gap.

There are other important differences between the fund in our paper and a large individual shareholder. Although they can both enjoy perks from special relationships with management, the fund's behaviour hurts both the firm's and the fund's shareholders, while the large individual shareholder's behaviour hurts only firm's shareholders. Thus, our environment

\footnotetext{
${ }^{10}$ The importance of shareholder vote has increased recently due to impending "proxy access" and "say-onpay" regulation, the move from plurality to majority voting schemes, the dismantlement of staggered boards, and the end to discretionary voting by brokers, see Choi, Fisch, and Kahan (2010).

${ }^{11}$ In some cases institutional investors outsource some of the research to proxy advisors (e.g., ISS and Glass, Lewis, \& Co.) but even then those proxy advisors do not seem to influence investors' votes in any substantial way, see Choi, Fisch, and Kahan (2010), and McCahery, Starks, and Sautner (2010).

${ }^{12}$ For models of the impact of incentive conflicts arising out of delegated portfolio management see, for example, Dasgupta and Prat (2008), and Vayanos and Woolley (2009). A very recent paper that examines the effect of the career concerns of portfolio managers on the effectiveness of exit as a governance mechanism is Dasgupta and Piacentino (2011).
} 
features an additional agency problem, between mutual funds and their investors, the effect of which is detrimental to both these investors and to the shareholders of portfolio firms. A final important distinction with the literature on large individual blockholders is that competition amongst funds for beneficial relationships with management is an important driver of our results.

The rest of the paper is organized as follows. The baseline model and our main results are presented in the next section. Section 3 considers various extensions of the model and provides microfoundations for some of our baseline assumptions. Section 4 concludes. All proofs are in the Appendix.

\section{Model}

For most of this paper we consider a single-period model with a large number of firms and two investment funds. We label the representative firm $n$. We label the two investment funds $L$ and $S$. Let $L(n), S(n)$, and $1-L(n)-S(n)$ denote the proportionate equity holdings in firm $n$ by fund $L$, fund $S$, and by the small direct investors respectively. We assume throughout that $L(n)>S(n)$, i.e., fund $L$ is "larger" than fund $S$.

Consider the representative firm $n$; it is run by an entrepreneur (we typically refer to him as the "manager" below). There is a single project whose payoff is either $R>0$ or 0 realized at the end of the period. The core need for investor activism arises out of an underlying moral hazard problem, which we model following Holmstrom and Tirole (1997) as follows: The probability of the positive payoff depends on managerial effort, which can be high or low, corresponding to probability of a positive payoff of $\rho_{h}$ and $\rho_{l}\left(<\rho_{h}\right)$, respectively. The manager enjoys a private benefit, $B$, when she does not exert effort. Each firm is equity financed, and the shareholders of the firm make a take-it-or-leave it contract offer to the manager. Projects are positive net present value (NPV) only conditional on managerial effort, and contracts between shareholders and the manager specify a payment to the manager, say $R_{m}(B)$, in the case where the payoff is $R$ and zero otherwise. Conditional on a good outcome the rest, $R-R_{m}(B)$, is split amongst the shareholders. It will be clear in the sequel that under the optimal contract $R_{m}(B)$ will be proportional to $B$.

At the beginning of the period there are two types of proposals brought forward: (i) shareholder proposals to decrease the private benefits of the manager of a firm from $B$ to $b^{+}<B$, (ii) managerial proposals to increase a manager's private benefits from $B$ to $b^{-}>B$. We refer to proposals of type (i) as value enhancing or positive, and to proposals of type (ii) as value reducing or negative. Hence, a yes vote to a positive proposal and a no vote to a negative proposals are actions against management, and we dub such actions as activism. All 
proposals arrive exogenously and are voted on by shareholders. The manager can observe votes, and the voting outcome for any proposal for any firm is determined by majority rule. ${ }^{13}$

As will be clear once the optimal contract is solved for amongst the firm's shareholders and the manager, direct shareholders always vote yes to a positive proposal and no to a negative proposal, that is against management. However, for the reasons informally described above, funds may or may not vote against management. To veto value enhancing proposals one needs $\tau \%$ of the present voters to vote no. There is a cost for the small shareholders to vote (but not for the funds), which we capture by letting $y$ be the random number of shares of other shareholders who choose to attend the vote, where $y \sim F_{n}$ in $[0,1-L(n)-S(n)]$. The veto power of each fund depends on how the other fund chooses to vote, so for such firm $n$ we accordingly define

$$
\begin{aligned}
q_{L S^{\prime}}(n) & =\mathbb{P}\left[\frac{L(n)}{L(n)+S(n)+y}>\tau\right]=\mathbb{P}\left[y<\frac{(1-\tau) L(n)-\tau S(n)}{\tau}\right] \\
q_{L^{\prime} S}(n) & =\mathbb{P}\left[\frac{S(n)}{L(n)+S(n)+y}>\tau\right]=\mathbb{P}\left[y<\frac{(1-\tau) S(n)-\tau L(n)}{\tau}\right] \\
q_{L S}(n) & =\mathbb{P}\left[\frac{L(n)+S(n)}{L(n)+S(n)+y}>\tau\right]=\mathbb{P}\left[y<\frac{(1-\tau)(L(n)+S(n))}{\tau}\right] .
\end{aligned}
$$

Hence $q_{L S^{\prime}}(n)$ is the veto power of $L$ when $S$ votes yes, $q_{L^{\prime} S}(n)$ is the veto power of $S$ when $L$ votes yes, and $q_{L S}(n)$ is the veto power of either $L$ or $S$ when they both vote no. By virtue of the fact that $L(n)>S(n)$, we can see that $q_{L S}(n)>q_{L S^{\prime}}(n)>q_{L^{\prime} S}(n)$, i.e., $L$ has more veto power alone than $S$ alone in any firm $n$. We impose a symmetry in the sense that to pass a value reducing proposal one needs, also, $\tau \%$ of the present voters to vote yes (recall that small shareholders vote $n o$ to value reducing proposals). ${ }^{14}$ Although we refer to $q_{L S}, q_{L S^{\prime}} q_{L^{\prime} S}$ as veto powers it should be clear that when the proposal is negative they refer to the "power" of the fund(s) to pass (and not veto) the proposal.

Firms have pensions plans for their employees. We assume that pensions administrations cannot be done in-house, so that firms must allocate it to one of the two investment funds. ${ }^{15}$ Shareholders pay the pensions administrations fee to the relevant investment fund: it is part of the cost of investing in the firm. ${ }^{16}$

At the beginning of the period (before the proposal arrives and any voting occurs) the firm is randomly allocated to a pensions administrator. Following this, the decision of which

\footnotetext{
${ }^{13}$ It can be shown that for our purposes either we require majority over the whole body of shareholders or just over those who choose to vote is immaterial.

${ }^{14}$ This symmetry is purely imposed for notational ease.

${ }^{15}$ This is reasonable for all but the largest firms, and could reflect some specific skills possessed by the investment fund manager.

${ }^{16}$ Thus, our assumption that the project has positive NPV conditional on managerial effort should be understood to be valid even taking into account the pensions management fee.
} 
investment fund to hire as pensions administrator falls into the hands of the firm's manager as follows. Following the vote on the proposal that arrives at the beginning of the period, the firm's manager decides whether to retain or replace the incumbent pension management fund. The fee is earned by that fund which is hired by the firm's manager following the vote. In this sense, the initial random allocation is entirely innocuous, since no fees are earned between the beginning of the period and the vote.

As the discussion to date makes clear, investment funds have a dual role. Their first role is to manage assets for institutional or individual investors. For this they receive a fee proportional to the net value of assets (NAV) managed at the end of each fiscal year. The value of their holdings depend on the cash flows that accrue to the shareholders of the firm. This is computed below. Their second role is to manage pension-plans of individual firms. For this they receive a fixed payment as described above. When a shareholder proposal arises at the beginning of the period, a given fund may be either the incumbent pensions administrator $(s=I)$, or the potential challenger for the pensions administration contract $(s=C)$. There are set-up costs to taking over a new pensions management contract (or, equivalently, there are relationship benefits within pensions administration) so that the fee paid by the shareholders to the pensions administrator following the vote translates into a state-dependent payoff. If the fund was in state $I$ before the vote, the rents earned are $x>0$, while if it was in state $C$ before the vote, the rents are $x^{\prime} \in(0, x)$. All our qualitative results hold for any $x, x^{\prime}$ where $0<x^{\prime}<x$.

\subsection{Contract between the firm's shareholders (direct and indirect) and the manager}

Since effort is essential for the project to have positive NPV, it is easy to solve directly for the optimal contract between the shareholders of the firm and the firm's manager. The timing, depicted in Fig. 1, is as follows: voting occurs which decides on the manager's private benefit and hence also on her payment $R_{m}$; the manager observes the voting outcome (as well as the individual votes) and decides on whether to exert effort or not. The manager's effort decision will be dictated by the familiar relationship: the manager exerts effort if $\rho_{h} R_{m}\left(B^{*}\right) \geq \rho_{l} R_{m}\left(B^{*}\right)+B^{*}$, for $B^{*} \in\left\{b^{+}, B, b^{-}\right\}$. This leads the shareholders to set $R_{m}\left(B^{*}\right)=B^{*} / \Delta \rho$, where $\Delta \rho=\rho_{h}-\rho_{l}$. Given this the manager always exerts effort, which yields payoff $R-B^{*} / \Delta \rho$ for the shareholders conditional on the success of the project.

Note that, in specifying the contracting problem, we have abstracted from the possibility of contractual payments contingent on the retention strategy used by the firm's manager. This is entirely realistic, since managerial compensation packages are rarely explicitly contingent on day-to-day business decisions. Nevertheless, we provide a discussion of richer contracting 
environments in Section 3.3. There we show that, within a reasonable class of enriched contracts that allow for payments contingent upon the manager's retention strategy, it is not possible to find a contract that increases the payoffs to firm's shareholders beyond what is achieved by the contract specified above.

Recall that the private benefit $B^{*}$ is equal to $B$ if the voting outcome is no to either a positive or a negative proposal. If the outcome is yes to a positive proposal the private benefit is $b^{+}<B$, while if the outcome is yes to a negative proposal it is $b^{-}>B$.

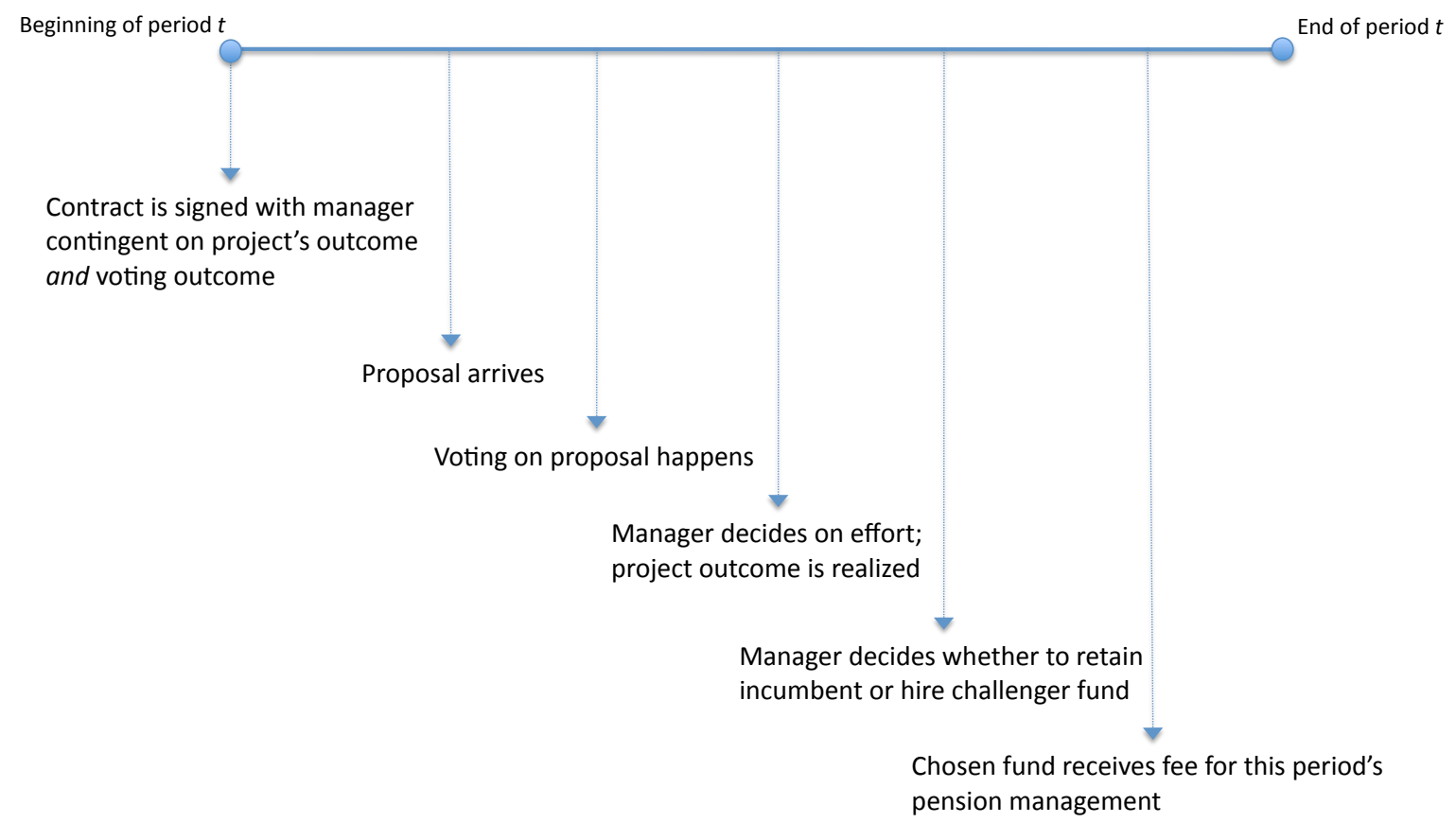

Figure 1: Timing.

We denote by $f\left(B^{*}\right)$ the returns earned by the fund if the private benefits following the vote at any period are $B^{*}$ net of any pensions administration fees. ${ }^{17}$ Let then,

$$
\begin{aligned}
& p^{+}=f\left(b^{+}\right)-f(B), \\
& p^{-}=f\left(b^{-}\right)-f(B),
\end{aligned}
$$

${ }^{17}$ In reality the function $f(\cdot)$ is different for $L$ and $S$ and different across firms, so that

$$
\begin{aligned}
& f_{n}^{L}\left(B^{*}\right)=y_{L} \times L(n) \times\left(R-B^{*} / \Delta \rho\right), \\
& f_{n}^{S}\left(B^{*}\right)=y_{S} \times S(n) \times\left(R-B^{*} / \Delta \rho\right),
\end{aligned}
$$

where $y_{L}, y_{S}$ are the per period management fees of $L, S$ respectively. However, for our analysis this distinction is superfluous. 
i.e., the incremental benefit (detriment) to funds by voting yes to a value enhancing (reducing) proposal. Function $f(\cdot)$ is linear and decreasing in its argument, hence $p^{+}>0>p^{-}$. Assume $p^{+} \in \mathcal{P}^{+}=\left\{p^{1}, \ldots, p^{K}\right\}$, and $p^{-} \in \mathcal{P}^{-}=\left\{-p^{1}, \ldots,-p^{K}\right\}$ where

$$
\mathbb{P}\left[p=p^{i}\right]=\pi^{i} / 2=\mathbb{P}\left[p=-p^{i}\right],
$$

for all $i \in\{1, \ldots, K\}$. Let $\mathcal{P}=\mathcal{P}^{-} \cup \mathcal{P}^{+}$.

In order to make our points in the simplest and cleanest possible environment, we assume for the baseline analysis that the large fund is quite large and the small fund is quite small, in the sense that for all firms $n, L(n) \geq(1-\tau) S(n) / \tau$, and $L(n) \geq \tau$. These imply, that $q_{L S^{\prime}}=1$, and $q_{L^{\prime} S}=0$, so that the large fund has full veto power whereas the small fund has none. In subsequent sections, we relax this extreme assumption, and show that our qualitative results remain similar.

\subsection{Equilibrium with no Disclosure}

When a fund does not need to disclose its vote to a regulator it can solve its decision problem per firm $n$ and so we drop the firm identifier for the rest of this subsection. Since firms are ex ante symmetric our results hold identically for all firms $n$. At the beginning of the period, before voting occurs, the firm's manager can commit to a particular replacement strategy conditional on how the two blockholders vote in that period. Note that commitment is fully credible given the payoffs of the model. We look for equilibria with commitment of the following form:

1. If $L$ votes yes and $S$ votes yes, retain (hire) $L$ with probability $\alpha$.

2. If $L$ votes yes and $S$ votes no, retain (hire) $L$ with probability $\alpha^{\prime}$.

3. If $L$ votes no and $S$ votes yes, retain (hire) $L$ with probability $\beta^{\prime}$.

4. If $L$ votes $n o$ and $S$ votes no, retain (hire) $L$ with probability $\beta$.

It is clear that it is without loss of generality to set $\alpha^{\prime}=0, \beta^{\prime}=1$ for $p \in \mathcal{P}^{+}$, and $\alpha^{\prime}=1, \beta^{\prime}=0$ for $p \in \mathcal{P}^{-}$. Let $x(s)$ be the pensions administration fee when a fund is in state $s \in\{C, I\}$, i.e., $x(C)=x^{\prime}<x=x(I)$; also let $\bar{s}$ be the compliment of $s$. We are now ready to state the main result of this section.

Proposition 1 Pre-disclosure the unique equilibrium behaviour of the manager is $\alpha=0, \beta=$ 1 , for $p \in \mathcal{P}^{+}$, and $\alpha=1, \beta=0$, for $p \in \mathcal{P}^{-}$, i.e., the manager gives the contract to $L$ if it votes pro-management, and does not give it to $L$ if it votes against management. In 
equilibrium $S$ always votes pro-management (i.e., no for $p>0$, yes for $p<0$ ) regardless of its state; $L$ votes against management for $x(s)<|p|$ and pro-management for $x(s) \geq|p|$ when in state $s \in\{C, I\}$.

We now flesh out some of the properties of this equilibrium. Our first observation, based on this corollary, is that the degree of support given to shareholder proposals by mutual funds is very limited in equilibrium (and in reverse to management proposals). This is due to a combination of a direct effect and a strategic effect. The direct effect is related to the arguments made against undisclosed proxy voting by mutual funds by the practitioner community. In equilibrium, voting against management leads to a loss of pensions administration contracts, and thus induces fund $L$ to vote pro-management for all but the most value-enhancing of proposals. The strategic effect is more subtle. The smaller fund $S$ perceives that it cannot really affect the outcome of the vote, and therefore the value of its portfolio, by voting with shareholders against management: if $L$ votes no, the proposal will be rejected anyway. However, given that in equilibrium, management always gives pensions administration contracts to the most pro-management fund, for high valued proposals, fund $S$ finds it optimal to always vote pro-management: there is always the event that for a sufficiently high valued proposal, fund $L$ will vote against management, and then, with this voting strategy, fund $S$ will obtain the contract. Thus, the limited support traditionally seen for shareholder proposals (and the increased support for management proposals), inasmuch as it derives from obstructive behaviour of mutual fund blockholders, is due to both a direct conflicts of interest and strategic interaction between different types of funds.

Our second observation is that, in this equilibrium, the firm's manager awards the pensions administration contract to the largest fund when both large and small funds vote pro-management. This is because, quite naturally, the firm's manager is mostly interested in influencing the behaviour of the largest blockholder. However, empirically, this implies that pensions administration contracts will over time cluster in the hands of the largest funds. For example, our model suggests, that it is the larger fund families (which, in a setting where large funds are essentially "closet-indexers") such as Fidelity, that end up with the largest degree of pensions administration business. While certainly there may be other reasons for such a clustering of pensions contracts among large blockholders, it is worth noting that this endogenous clustering of business ties seems supported by the data, see, for example, Davis and $\operatorname{Kim}(2007)$.

In addition, it is important to note that this has implications for the effect of disclosure. As our results below will indicate, our model will imply that post-disclosure funds with more business ties will be less activist. But, if it is exactly the largest funds that have the most business ties, it will be the largest funds that will be least activist, spelling further difficulty 
for shareholder activism.

\subsection{Equilibrium with Disclosure}

We now solve for the equilibrium of the model when the funds do need to disclose their voting policy to a regulator and their votes are ex post made public. In particular, for each proposal in $\mathcal{P}$, each fund must announce whether it will vote yes or no, unconditional on whether it is an incumbent or a challenger in the firm, and their votes for each firm for each proposal are observable by the regulator. The declaration of voting strategies is a feature of the new SEC regulations, and therefore we treat it as given.

When voting policies and ex post votes are made public, we must consider market and regulatory reactions to observed variables. In the baseline model, we assume that investors in mutual funds are inactive, in the sense that they do not react to voting policies or observed votes. This can be justified on the grounds that mutual fund investors do not understand the value inherent in various corporate governance proposals. In addition, empirically, there seems to be no established relationship between investor flows into mutual funds and mutual fund activism. ${ }^{18}$ Instead, we focus on the case of regulatory penalties.

Mutual funds are vested with the fiduciary responsibility to vote their proxies in a way that is beneficial to their shareholders, and the SEC is able to monitor such voting following disclosure. Following disclosure, the SEC is able to take legal action against mutual funds who are demonstrably in violation of their fiduciary responsibilities on the basis of their observed proxy votes. We assume, realistically, that the SEC is unable to verify in court whether a specific proposal is value enhancing or not, i.e., the sign of $p$ is non-verifiable. However, for a given proposal, the SEC is easily able to demonstrate in court that a fund is in violation of fiduciary responsibility if it votes in a conflicted manner, i.e., in a manner that relies on the existence of pensions management relationships. In the proof of Proposition 2 below, we compute a lower bound on the regulatory penalties which would eliminate conflicted voting post-disclosure, and assume that the penalties in the model satisfy this lower bound. It is worth pointing out that Davis and Kim (2007) find that there is no conflicted voting postdisclosure. Thus, we effectively calibrate our model along this particular dimension to Davis and Kim (2007)'s findings. In the extension of Section 3.1, we microfound the lack of market reaction, and provide an alternative punishment technology that could be used instead to support our equilibrium.

\footnotetext{
${ }^{18}$ The only empirical analysis on this point that we are aware of is by Ashraf and Jayaraman (2007), who find that there is very limited evidence for a flow-response to observed activism. The slope of the activismflow relationship is an order of magnitude smaller than that of the well-known flow-performance relationship. When broken down by categories of proposals, it is statistically significant for only one out of seven types of shareholder proposals considered.
} 
As before, at the beginning of the period and before voting occurs the firm's manager can commit to a particular firing strategy conditional on how the two blockholders vote. We look for equilibria where managers follow symmetric strategies across firm, and each manager follows a commitment strategy of the same form as in the pre-disclosure case. Again, it is without loss of generality to set $\alpha^{\prime}=0, \beta^{\prime}=1$ for $p \in \mathcal{P}^{+}$, and $\alpha^{\prime}=1, \beta^{\prime}=0$ for $p \in \mathcal{P}^{-}$. We are now ready to state the main result of this section.

Proposition 2 Post-disclosure and for regulatory penalty at least $x-x^{\prime}$ the unique equilibrium behaviour of the manager is $\alpha=0, \beta=1$, for $p \in \mathcal{P}^{+}$, and $\alpha=1, \beta=0$, for $p \in \mathcal{P}^{-}$, i.e., the manager gives the contract to $L$ if it votes pro-management, and does not give it to $L$ if it votes against management. In equilibrium $S$ always votes pro-management (i.e., no for $p>0$, yes for $p<0$ ) regardless its fraction of firms that are clients; $L$ votes against management for $\bar{x}<|p|$ and pro-management for $\bar{x} \geq|p|$, where

$$
\bar{x}=r^{L} x+\left(1-r^{L}\right) x^{\prime}
$$

and $r^{L}$ is the fraction of firms in which $L$ is the incumbent pensions fund manager.

In this equilibrium, fund $S$ always votes pro-management, thus engaging (as before) in no activism. The fund $L$ votes against management for proposals $p \in \mathcal{P}$ that satisfy $|p|>\bar{x}$, and for management for all other proposals, regardless of whether it is engaged in a pensions management relationship with the firm or not.

We now proceed to analyze the implications of this result. We make two crucial comparisons. First, we compare the level of delegated activism before and after disclosure. Second, we provide a clear empirical implication for the relationship between the level of activism and the business ties of mutual funds.

First, a comparison between the case pre and post-disclosure suggests that disclosure will have a nuanced effect on the level of delegated activism. For fund $S$, disclosure makes no difference whatsoever. For fund $L$, disclosure makes a difference in the following way:

1. For $|p| \in\left(0, x^{\prime}\right)$, both before and after disclosure, fund $L$ voted pro-management, and thus disclosure makes no difference to the level of delegated activism.

2. For $|p| \in\left(x^{\prime}, \bar{x}\right)$, pre-disclosure fund $L$ voted against management for non-clients and with management for clients, but post-disclosure fund $L$ votes pro-management for both clients and non-clients. Thus, for this range of proposals, disclosure leads to less delegated activism by fund $L$.

3. For $|p| \in(\bar{x}, x)$, pre-disclosure fund $L$ voted against management for non-clients and with management for clients, but post-disclosure fund $L$ votes against management for 
both clients and non-clients. Thus, for this range of proposals, disclosure leads to more delegated activism by fund $L$.

4. For $|p| \in(x, \infty)$, both pre and post-disclosure, fund $L$ votes against management, and thus disclosure again makes no difference to the level of delegated activism.

Thus, whether disclosure increases or diminishes delegated activism depends crucially on the process generating the arrival of future proposals for changes in corporate governance, and how they relate to the regions $\left(x^{\prime}, \bar{x}\right)$ and $(\bar{x}, x)$. Note that since $\bar{x}=r^{L} x+\left(1-r^{L}\right) x^{\prime}$, the relative sizes of these regions are determined by the measure of client relationships for fund $L, r^{L}$. For a given $r^{L}$, the higher the probability of the absolute value of proposals falling in the interval $\left(x^{\prime}, \bar{x}\right)$, the less beneficial will be disclosure for the level of delegated activism. Formally, we can state:

Corollary 1 For any given $r^{L}$, let $\Pi^{0}$ the set of $\left\{\pi^{i}\right\}_{i=\{1, \ldots, K\}}$, for which the amount of activism is the same pre and post-disclosure on average, and let $\underline{\pi}=\mathbb{P}_{\Pi^{0}}\left[p \in\left(x^{\prime}, \bar{x}\right)\right]$. Then all distributions for which the same probability exceeds $\underline{\pi}$ will have the feature that disclosure reduces the level of delegated activism.

This finding suggests that empirical analyses which compare the level of activism pre and post-disclosure may well fail to arrive at uniform conclusions. Even if voting could reliably be inferred in the pre-disclosure data, the conclusions should depend critically on the proposal distribution, which may vary over time and across datasets. ${ }^{19}$

For example, Cremers and Romano (2009) find that for EEIC proposals, there is some evidence that post-disclosure overall mutual fund support for management increased. This is consistent with our results, for example, if these proposals satisfy the condition in point (2) above.

A second implication arising from our analysis above is that there will be systematic differences amongst funds in their post-disclosure voting policies depending on their level of business connections. It follows from the analysis above that fund $L$ will vote more promanagement the bigger is $\bar{x}$. But $\bar{x}$ is increasing in $r^{L}$, the measure of business relationships amongst the portfolio firms of fund $L$. Thus, we can state:

Corollary 2 Following disclosure, the level of overall delegated activism for fund $L$ will be smaller if it has many business connections.

This finding ties in well with the finding in Davis and Kim (2007) that overall, voting policies against management will be more muted for funds that have more business connections.

\footnotetext{
${ }^{19}$ As mentioned in the introduction the distribution of proposals may change pre- and post-disclosure.
} 


\section{Extensions}

In this section we consider several natural extensions to our simple baseline model.

\subsection{Endogenous investor inertia}

In the baseline model we assumed that small mutual fund investors were inactive in monitoring their mutual funds for activism. This assumption, while realistic, can be justified by a simple model of investor learning about mutual funds. We augment the baseline model by introducing types of mutual funds, and make explicit the degree to which investors comprehend the nature of corporate governance in our model. There are two islands: $L$ and $S$. On each island there is one fund, which can be of two types. The honest type of fund naively maximizes the payoff of the funds' shareholders. The strategic type of fund takes into account more considerations in order to maximize its profits. Investors in island $i \in\{L, S\}$ can only invest in island $i$ 's fund, and can only observe policies and votes of that fund. The two funds, $L$ and $S$, in turn, interact with a continuum of firms on island $M$, where the game between firms' managers and the two funds is as described in the baseline model.

Investors do not know if their funds are of the honest or strategic type, but must assign sufficiently high probability to the fund being of the honest type in order to invest in their fund to begin with instead of taking all their money out and moving to the other island (no third option available). Investors do not observe the values of proposals, but observe instead category labels for each proposal, i.e., there is a one-to-one function $C: \mathcal{P} \mapsto \mathcal{C}$ (e.g., $\mathcal{C}$ could be the first $2 \cdot K$ letters of the English alphabet, for $K<13)$; let also $P(c)=\{p \in \mathcal{P}: C(p)=$ $c$ \} be the inverse function. Funds' investors do not know (and cannot infer) the mapping $C$, but in all other respects they understand the baseline model.

Then the honest type of fund will (by definition) announce a voting policy that is as follows: yes for $c:\left\{P(c) \in \mathcal{P}^{+}\right\}$, and no for all other proposals. The strategic type of fund announces a voting policy as follows: yes for $c:\{P(c) \in \mathcal{S}\}$ and no otherwise, where $\mathcal{S}$ is not $\mathcal{P}^{+}$in general, especially, it can be the case that $\mathcal{S} \cap \mathcal{P}^{-} \neq \varnothing$. Importantly, since investors cannot tell which labels correspond to value enhancing vs value reducing proposals, they cannot tell apart any voting strategy where the cardinality of $\mathcal{S}$ is equal to the cardinality of $\mathcal{P}^{+}$, and this is the case for symmetric positive and negative proposals. So, for appropriately chosen off equilibrium beliefs, ${ }^{20}$ there is a pooling equilibrium where the baseline equilibrium of Proposition 3 follows and leads to no investor learning, and hence no market punishment.

In the following subsections we will only deal with the case of positive $p>0$ proposals and so $\mathcal{P}=\mathcal{P}^{+}$for the remainder of the paper. The extension for negative proposals is

\footnotetext{
${ }^{20}$ Such beliefs are the ones that assign probability one to a fund being dishonest if it votes differently in the cross section of firms, and lead to a sufficient (see proof of Proposition 3) market punishment.
} 
straightforward.

\subsection{Funds of comparable sizes: the case of smaller large blocks}

The baseline model was presented under the extreme, but extremely convenient, assumption that $L(n)$ was large enough and $S(n)$ was small enough that fund $L$ had full veto power, while fund $S$, had no veto power whatsoever. While it is not unreasonable to assume that small funds behave strategically essentially as if they have no veto power, the assumption of full veto power is clearly a stylization, assumed to deliver our core results in the simplest possible framework. We show next that if we make the large fund less influential, our core results are enforced. Indeed, we shall see that under certain conditions activism by the influential fund actually falls in this case. The overall level of activism may rise or fall, depending on the parameters.

We know from Proposition 1 that if $L(n) \geq(1-\tau) S(n) / \tau$, and $L(n) \geq \tau$, which imply that $q_{L^{\prime} S}=0$, and $q_{L S^{\prime}}=q_{L S}=1$, respectively, the manager's optimal strategy is $\alpha=0, \beta=1$ (i.e., the manager hires (retains) the large fund when it votes in favor of management, and does not hire (fires) the large fund when it votes against management, regardless of what the small fund does). We now consider the case in which $L(n) \geq(1-\tau) S(n) / \tau$, and $L(n)<\tau$, which imply that $q_{L^{\prime} S}=0$, and $q_{L S^{\prime}}<q_{L S} \leq 1$, i.e., though $S$ still has no veto power, now $L$ does not have sufficient blockholdings to have full veto power.

We consider the same commitment strategy by managers as in Section 2, and derive the equilibrium behavior of all players (managers, large fund, small fund) both pre and postdisclosure. Let $s \in\{C, I\}$ the state of $L$, hence $\bar{s}$ of $S$, and $p=f(b)-f(B)>0$. The following proposition shows that pre-disclosure and in the case of smaller large blocks the $\alpha=0, \beta=1$ strategy is not optimal for the manager for some proposals.

Proposition 3 Pre-disclosure the unique equilibrium behaviour of the manager is $\alpha=0$ for all $p$, and

$$
\beta=\left\{\begin{array}{rll}
1, & \text { for } & p>\hat{p}(s), \\
\hat{\beta}(s), & \text { for } & p \leq \hat{p}(s) .
\end{array}\right.
$$

In equilibrium, $S$ votes yes, i.e., against management, for proposals such that $p \in\left(\hat{p}(s), x(s) / q_{L S}\right)$, and votes no otherwise. L votes yes for $p>x(s) / q_{L S}$ and no for $p<x(s) / q_{L S} . \hat{\beta}(s)$ and $\hat{p}(s)$ are defined as follows:

$$
\hat{\beta}(s)=\frac{x(\bar{s}) q_{L S}}{q_{L S}[x(s)+x(\bar{s})]-q_{L S^{\prime}} x(s)}<1,
$$




$$
\hat{p}(s)=\frac{x(s) x(\bar{s})}{q_{L S}[x(s)+x(\bar{s})]-q_{L S^{\prime}} x(s)}<\frac{x(s)}{q_{L S}}<\frac{x(s)}{q_{L S^{\prime}}} .
$$

Since the large fund is smaller than in the baseline case, the bias towards employing large funds is mitigated. This has the interesting implication that the small fund is now hired (retained) with positive probability even if both the funds vote no, i.e., pro-management, and results to:

Corollary 3 Having smaller large blockholdings increases activism by the small fund relative to the baseline case where the large fund had full veto power over proposals.

The intuition for this is that since the small fund can now affect the voting outcome (not by itself but by siding either with the large fund or with other shareholders) a vote against management is a credible threat which the small fund uses in equilibrium. Moreover, if we assume that $L(n)+S(n) \geq \tau \Rightarrow q_{L S}=1$ then for proposals in the region $(\hat{p}(s), x(s))$ the probability of a no voting outcome (to a positive proposal) is one in the baseline case, and $q_{L S^{\prime}}<1$ in the case of funds of comparable sizes (and in every other region the probability of a no voting outcome is the same). Hence we state the following:

Corollary 4 If institutional investors' holdings are significant on aggregate (i.e., together the large fund and the small fund have full veto power), the existence of funds of comparable sizes mitigates the harm to other shareholders (caused by the conflict of interest of the funds).

This is a direct consequence of the fact that the small fund becomes more active exactly because it can affect the outcome, while the large fund's actions remain the same. Now for $L(n)+S(n)<\tau \Rightarrow q_{L S}<1$ we report results in Tables 1 and 2. It is immediate then that:

Corollary 5 If institutional investors' holdings are not significant on aggregate, having smaller large blockholdings reduces activism by the large fund relative to the baseline case where the large fund had full veto power over proposals.

\begin{tabular}{|l||c|c|c||c|c|c|}
\hline \multirow{2}{*}{\multicolumn{1}{|l||}{$p \in$}} & \multicolumn{3}{c||}{$0=q_{L^{\prime} S}<q_{L S^{\prime}}=q_{L S}=1$} & \multicolumn{3}{c|}{$0=q_{L^{\prime} S}<q_{L S^{\prime}}<q_{L S}<1$} \\
\cline { 2 - 8 } & $(S, L)$ vote & $(\alpha, \beta)$ & $\mathbb{P}[$ no $]$ & $(S, L)$ vote & $(\alpha, \beta)$ & $\mathbb{P}[$ no $]$ \\
\hline \hline$(0, \hat{p}(s))$ & $($ no, no $)$ & $(0,1)$ & 1 & $($ no, no $)$ & $(0, \hat{\beta}(s))$ & $q_{L S}$ \\
\hline$(\hat{p}(s), x(s))$ & $($ no, no $)$ & $(0,1)$ & 1 & $($ yes, no $)$ & $(0,1)$ & $q_{L S^{\prime}}$ \\
\hline$\left(x(s), x(s) / q_{L S}\right)$ & $($ no, yes $)$ & $(0,1)$ & 0 & $($ yes, no $)$ & $(0,1)$ & $q_{L S^{\prime}}$ \\
\hline$\left(x(s) / q_{L S}, x(s) / q_{L S^{\prime}}\right)$ & $($ no, yes $)$ & $(0,1)$ & 0 & $($ no, yes $)$ & $(0,1)$ & 0 \\
\hline
\end{tabular}

Table 1: Equilibria for the baseline case and smaller large blocks assuming $x(s)>\hat{p}(s)$. 


\begin{tabular}{|l||c|c|c||c|c|c|}
\hline \multirow{2}{*}{\multicolumn{1}{|c||}{$p \in$}} & \multicolumn{2}{|c||}{$0=q_{L^{\prime} S}<q_{L S^{\prime}}=q_{L S}=1$} & \multicolumn{3}{c|}{$0=q_{L^{\prime} S}<q_{L S^{\prime}}<q_{L S}<1$} \\
\cline { 2 - 8 } & $(S, L)$ vote & $(\alpha, \beta)$ & $\mathbb{P}[$ no $]$ & $(S, L)$ vote & $(\alpha, \beta)$ & $\mathbb{P}[$ no $]$ \\
\hline \hline$(0, x(s))$ & $($ no, no $)$ & $(0,1)$ & 1 & $($ no, no $)$ & $(0, \hat{\beta}(s))$ & $q_{L S}$ \\
\hline$(x(s), \hat{p}(s))$ & $($ no, yes $)$ & $(0,1)$ & 0 & $($ no, no $)$ & $(0, \hat{\beta}(s))$ & $q_{L S}$ \\
\hline$\left(\hat{p}(s), x(s) / q_{L S}\right)$ & $($ no, yes $)$ & $(0,1)$ & 0 & $($ yes, no $)$ & $(0,1)$ & $q_{L S^{\prime}}$ \\
\hline$\left(x(s) / q_{L S}, x(s) / q_{L S^{\prime}}\right)$ & $($ no, yes $)$ & $(0,1)$ & 0 & $($ no, yes $)$ & $(0,1)$ & 0 \\
\hline
\end{tabular}

Table 2: Equilibria for the baseline case and smaller large blocks assuming $x(s)<\hat{p}(s)$.

The intuition for this is that voting pro-management in the case of absolute majority blocks ensures (in equilibrium) that the large fund remains or becomes the pensions fund administrator, but eliminates the possibility of portfolio value improvements. So when the large fund does not hold absolute majority blocks, then voting pro-management guarantees (in the above equilibrium) continuation/hiring and pensions administration, but does not eliminate the possibility of portfolio value improvement, exactly because the funds are not pivotal on aggregate. Thus, there is, perversely, greater incentive at the margin for fund $L$ to vote pro-management.

Maintaining the assumption that $L(n)+S(n)<\tau$, so that the two mutual funds together do not have full veto power, note that proposals always pass in the baseline case if $p>x(s)$, but in the smaller large blocks case they pass for sure only if $p>x(s) / q_{L S}$. But, for $p<x(s)$, in the baseline case, proposals always fail. In the smaller large blocks case, if $p<x(s) / q_{L S}$, proposals pass with positive probability. So:

Corollary 6 In comparison to the baseline case, the degree of successful activism can be either smaller or larger when institutional investors' holdings are not significant on aggregate.

In particular, there exist distributions of proposals that can either increase, decrease, or not change the probability of proposals acceptance. This also implies that there is not a uniform relationship between the total degree of ownership by mutual funds and the likelihood of shareholder proposals passing. For example, since the baseline case involved $L(n)>\tau$ and this case involves $L(n)+S(n)<\tau$, there is lower overall mutual fund shareholdings in this latter case with smaller largest blocks. Thus, it is possible to make the probability of overall passage of (positive) proposals lower with lower mutual fund ownership. This suggests that caution is required in making inferences from the relationship between overall mutual fund ownership and the degree of shareholder activism. Hence:

Corollary 7 Higher institutional ownership will not necessarily translate into more promanagement voting outcomes on specific proposals. 
With disclosure and smaller large blocks we have a very similar result to Proposition 3. So we state the following result without proof.

Proposition 4 Post-disclosure and for regulatory penalty at least $x-x^{\prime}$ the unique equilibrium behaviour of the manager is $\alpha=0$ for all proposal $p$, and

$$
\beta= \begin{cases}1, & \text { for } p>\bar{p} \\ \bar{\beta}, & \text { for } p \leq \bar{p}\end{cases}
$$

In equilibrium, $S$ votes yes, i.e., against management, for proposals such that $p \in\left(\bar{p}, \bar{x} / q_{L S}\right)$, and votes no otherwise. L votes yes for $p>\bar{x} / q_{L S}$ and no for $p<\bar{x} / q_{L S} \cdot \bar{\beta}, \bar{p}, \hat{x}$, and $\bar{x}$ are defined as follows:

$$
\begin{aligned}
\bar{\beta} & =\frac{\hat{x} q_{L S}}{q_{L S}[\bar{x}+\hat{x}]-q_{L S^{\prime}} \bar{x}}<1, \\
\bar{p} & =\frac{\bar{x} \hat{x}}{q_{L S}[\bar{x}+\hat{x}]-q_{L S^{\prime}} \bar{x}}<\frac{\bar{x}}{q_{L S}}<\frac{\bar{x}}{q_{L S^{\prime}}}, \\
\hat{x} & =\left(1-r^{L}\right) x+r^{L} x^{\prime} \\
\bar{x} & =r^{L} x+\left(1-r^{L}\right) x^{\prime},
\end{aligned}
$$

where $r^{L}$ is the fraction of firms in which $L$ is the incumbent pensions fund manager.

Every statement we made regarding the pre-disclosure equilibrium in the case of smaller large blocks also holds post-disclosure if one replaces, $\hat{\beta}(s), \hat{p}(s), x(s), x(\bar{s})$ with $\bar{\beta}, \bar{p}, \hat{x}, \bar{x}$, respectively. The pre and post-disclosure comparison follows exactly the same pattern as in the baseline case of Section 2.3, i.e., the overall effect of disclosure is ambiguous in aligning the incentives of the funds with those of the rest of the firms' shareholders.

\subsection{Richer contracts}

In the analysis to date, we have assumed that managerial compensation can only be based on observed cash-flows. In other words, the firm's shareholders cannot contract on their manager's replacement strategy with regard to pensions administrators, summarized in our notation by $\left(\alpha, \alpha^{\prime}, \beta, \beta^{\prime}\right)$. It is worth noting that such non-contractibility of individual business decisions is quite realistic and can be justified by various reasonable frictions. In addition, if we allowed each firm's shareholders to contract on $\left(\alpha, \alpha^{\prime}, \beta, \beta^{\prime}\right)$ the resulting contracting problem would be highly non-standard. For example, if fund $S$ is the current incumbent 
pensions administraor, it would always prefer for the manager to unconditionally retain the current pensions manager $\left(\alpha=\alpha^{\prime}=\beta=\beta^{\prime}=0\right)$, while fund $L$ would prefer for the manager to unconditionally replace the current pensions administrator $\left(\alpha=\alpha^{\prime}=\beta=\beta^{\prime}=1\right)$; Small shareholders, on the other hand, would be indifferent amongst a class of strategies that do not condition replacement on voting, e.g. $\alpha=\alpha^{\prime}=\beta=\beta^{\prime}=\frac{1}{2}$. The outcome of any potential contracting negotiation would depend on the relative bargaining power of at least three different principals in addition to the manager, resulting in a rich and non-standard contracting problem. While the analysis of this problem is beyond the scope of our exercise, we can shed some light on one important special case, in which the optimal contract is determined purely from the perspective of small shareholders. In this section, we show that, within the class of contracts that induce effort by the manager regardless of his replacement strategy, the optimal contract leaves at least as much agency rent to the manager as the contract used in our baseline model.

Small shareholders are indifferent between a class of unconditional replacement strategies (including the three noted above). Consider contracts under which, if cash flows are $R$, small shareholders offer a payoff of $R_{1}^{m}$ to the manager if he commits to an unconditional replacement strategy (which we denote by $\sigma=u$ ), and a payoff of $R_{2}^{m}$ if he instead commits to a contingent replacement strategy (which we denote by $\sigma=c$ ). All payoffs are zero in case of zero cash flows.

It is clear that under such a contract, if the manager commits to a contingent replacement strategy, he will choose $\alpha=\alpha^{\prime}=0, \beta=\beta^{\prime}=1$ as in the baseline model, inducing the same voting behaviour by the funds as in Proposition 1. If, on the other hand, he commits to an unconditional replacement strategy, then funds will always vote against management (to enhance portfolio values). Consider a firm where the current level of managerial private benefits is $B$, and consider the proposal $p$ which intends to reduce these private benefits to $b$ and satisfies the following conditions: fund $L$ votes against $p$ under $\sigma=c$, but for $p$ under $\sigma=u$. The other cases are uninteresting from a contracting perspective. Any contract that gives the manager incentives to choose $\sigma=u$ and, regardless of this choice, provides incentives to exert effort, must satisfy the following incentive compatibility constraints. ${ }^{21}$ First, effort and $\sigma=u$ must be preferred to no-effort and $\sigma=u$, so that:

$$
\rho_{h} R_{1}^{m} \geq \rho_{l} R_{1}^{m}+b
$$

\footnotetext{
${ }^{21}$ Formally, we are looking for contracts that induce effort both on and off the equilibrium path. This could be justified by, for example, a small proportion of managers being committed types who always follow contingent commitment strategies along with some very large negative utility for shareholders from negative payoffs.
} 
Second, effort and $\sigma=u$ must be preferred to effort and $\sigma=c$, so that:

$$
\rho_{h} R_{1}^{m} \geq \rho_{h} R_{2}^{m}
$$

Third, effort and $\sigma=u$ must be preferred to no-effort and $\sigma=c$, so that:

$$
\rho_{h} R_{1}^{m} \geq \rho_{l} R_{2}^{m}+B
$$

Finally, effort and $\sigma=c$ must be preferred to no-effort and $\sigma=c$, so that:

$$
\rho_{h} R_{2}^{m} \geq \rho_{l} R_{2}^{m}+B
$$

These constraints jointly imply that $R_{1}^{m} \geq R_{2}^{m} \geq \frac{B}{\Delta \rho}$, and thus the resulting contract implies no less a payment to the managers than the contract used in the baseline model.

\subsection{Multi-period model}

\subsubsection{No disclosure}

Our baseline analysis was carried out in a single-period environment. We now extend the analysis by considering a $T$ period model. There is, as before, a large number of firms and two investment funds. Let $n$ be the representative firm, and let $L(n)$ and $S(n)$ represent the shareholdings of the two funds. ${ }^{22}$ We assume that each firm is run by a sequence of short-lived entrepreneurs, one per period. During each period $t$, there is a single project whose payoff is either $R>0$ or 0 realized at the end of period $t$. Each period $t$ is just like the single-period described in the baseline model above. At the beginning of each period, shareholders bring forth a proposal, which is voted on. The private benefits of the manager, now indexed by $t$, are determined by the outcome of this vote, and the pensions administration fee for period $t$ is earned by that fund that is retained or hired by the manager following the vote at the beginning of period $t$. We assume that funds discount the future at the rate of $\delta \in[0,1]$. To keep the model tractable, we assume that for each $t: p_{t} \in \mathcal{P}=\left\{p^{1}, \ldots, p^{K}\right\}$, where

$$
\mathbb{P}\left[p_{t}=p^{i} \mid p_{1}, \ldots, p_{t-1}\right]=\mathbb{P}\left[p_{t}=p^{i}\right]=\pi^{i}
$$

for all $t \in\{1, \ldots, T\}$ and $i \in\{1, \ldots, K\}$. In other words, proposals arrive in an i.i.d fashion over time, and in an i.i.d. fashion over the cross-section of firms. Since the manager is short-lived, the optimal contract between shareholders and manager is unchanged.

\footnotetext{
${ }^{22}$ We therefore do not index the shareholdings by time. At substantial notational cost, we could let shareholding evolve in our model over time, without changing the core qualitative results.
} 
We solve for the equilibrium of the $T$ period model when the funds do not need to disclose their vote to a regulator. We also assume, as in the baseline case that $L(n) \geq(1-\tau) S(n) / \tau$, and $L(n) \geq \tau$. Without disclosure, a fund can solve its decision problem over time per firm $n$ and so we drop the firm identifier for the rest of this section. Since firms are ex ante symmetric our results hold identically for all firms $n$.

At the beginning of each period $t$, before voting has occurred the firm's manager can commit to a particular voting strategy conditional on how the two blockholders vote in that period. Note that, since the firm's manager is short-lived, the commitment is fully credible. Extending the analysis of the one-period model, we now look for equilibria with commitment of the following form:

1. If $L$ votes yes and $S$ votes yes, retain (hire) $L$ with probability $\alpha_{t}$.

2. If $L$ votes yes and $S$ votes no, retain (hire) $L$ with probability $\alpha_{t}^{\prime}$.

3. If $L$ votes no and $S$ votes yes, retain (hire) $L$ with probability $\beta_{t}^{\prime}$.

4. If $L$ votes $n o$ and $S$ votes $n o$, retain (hire) $L$ with probability $\beta_{t}$.

It is clear that it is without loss of generality to set $\alpha_{t}^{\prime}=0$ and $\beta_{t}^{\prime}=1$ for all $t \in\{1, \ldots, T\}$. We are now ready to state the main result of this section.

Proposition 5 Pre-disclosure the unique equilibrium behavior for any $t \in\{1, \ldots, T\}$ and for any firm $n$ is as follows:

(i) The t-period manager sets $\alpha_{t}=0$ and $\beta_{t}=1$, so she gives the contract to $L$ if it votes pro-management, and she does not give it to $L$ if it votes against management.

(ii) $S$ always votes pro-management, while $L$ votes against management for period $t$ proposals $p_{t}$ such that $x\left(s_{t}^{n}\right)<p_{t}$, and votes pro-management otherwise, where $s_{t}^{n} \in\{C, I\}$ is the state of $L$ in firm $n$ at time $t$.

Actually from the proof of Proposition 5 we have that the continuation payoff of $L$ at period $t$ onwards is

$$
\Pi_{t}^{L}(s)=\sum_{i=1}^{K} \pi^{i} \Pi_{t}^{L}\left(s, p^{i}\right)
$$

for $t=1, \ldots, T, s \in\{C, I\}$. Also

$$
\Pi_{t}^{L}(C, p)= \begin{cases}f(b)+\delta \Pi_{t+1}^{L}(C), & x^{\prime}<\tilde{p} \\ x^{\prime}+f(B)+\delta \Pi_{t+1}^{L}(I), & x^{\prime} \geq \tilde{p}\end{cases}
$$




$$
\Pi_{t}^{L}(I, p)= \begin{cases}f(b)+\delta \Pi_{t+1}^{L}(C), & x<\tilde{p} \\ x+f(B)+\delta \Pi_{t+1}^{L}(I), & x \geq \tilde{p}\end{cases}
$$

where

$$
\tilde{p}=p+\delta\left[\Pi_{t+1}^{L}(C)-\Pi_{t+1}^{L}(I)\right]
$$

for $p \in \mathcal{P}, t=1, \ldots, T$, and $\Pi_{T+1}^{L}(C)=\Pi_{T+1}^{L}(I)=0$.

Corollary 8 The more patient $L$ is, i.e., for higher values of $\delta$, the less activism it will exert, in the sense of voting down proposals that increase shareholder value.

\subsubsection{Disclosure}

The treatment of the case of disclosure is very similar, and leads to the following result which is qualitatively very similar to that of Proposition 5.

Proposition 6 Post-disclosure and for regulatory penalty at least $x^{\prime}-x$ (per period) the unique equilibrium behavior for any $t \in\{1, \ldots, T\}$ is as follows:

(i) Any t-period manager sets $\alpha_{t}=0$ and $\beta_{t}=1$, so she gives the contract to $L$ if it votes pro-management, and she does not give it to $L$ if it votes against management.

(ii) $S$ always votes pro-management, while $L$ votes against management for period $t$ proposals $p_{t}$ such that $\tilde{x}\left(r_{t}\right)<p_{t}$, and votes pro-management otherwise, where $r_{t}$ is the fraction of $L$ 's clients at $t$, and

$$
\tilde{x}\left(r_{t}\right)=r_{t} x+\left(1-r_{t}\right) x^{\prime}
$$

Thus, as in the single period baseline case, the behaviour of the fund post-disclosure is driven by the "average" firm in the its portfolio, where the average is computed using the evolving fraction of clients vs non-clients $r_{t}$.

\section{Conclusion}

Mutual funds hold large blocks of shares in many major corporations. Practitioners and regulators alike have been concerned that mutual funds use their proxy votes in a pro-management manner in order to retain lucrative pensions administration contracts, thus hindering share-

holder value. Such concerns led the SEC to mandate the disclosure of mutual fund proxy votes starting in 2003. Relatively little is known about the impact of such regulation on the 
behaviour of mutual funds and thus on the potential welfare implications of such regulation. An important paper by Davis and Kim (2007) suggests that, following mandatory disclosure, mutual funds with large numbers of business connections have become less activist, raising the question of whether mandatory disclosure has achieved what it set out to do. The issue is of significant current relevance, as similar regulatory changes are now in consideration outside the US. Yet, the absence of data on mutual fund voting prior to disclosure makes it difficult to empirically delineate the effect of mandatory disclosure.

To bridge this gap, we present a very simple model of mutual fund proxy voting prior to and following mandatory disclosure. Our model, which incorporates a stylized basis for conflicted proxy voting by mutual funds, provides clean predictions on how funds would vote both prior and subsequent to disclosure. Our results provide a theoretical foundation for why activism by mutual funds is very limited, both before and after mandatory disclosure. In addition, we are able to to evaluate the effect of mandatory disclosure on the overall level of mutual fund activism. We show that mandatory disclosure can actually increase the degree of pro-management voting by mutual funds for low to intermediate valued shareholder proposals. Our results also establish that, following mandatory disclosure, mutual funds with a high degree of business connections will be less activist, thus providing theoretical justification

for Davis and Kim (2007)'s empirical finding. In addition, our model generates a number of testable predictions that may be examined in the data both pre- and post-disclosure.

\section{Appendix}

Proof of Proposition 1: Given $p=f(b)-f(B)$, let $L$ be in state $s$, and hence $S$ in state $\bar{s}$.

1. Positive proposal: $p \in \mathcal{P}+$, i.e. $p>0$

- If $S$ votes yes, $L$ votes yes if

$$
\alpha x(s)+f(b)>x(s)+f(B) \text {, i.e., if }(1-\alpha) x(s)<p,
$$

and votes no otherwise.

- If $S$ votes $n o, L$ votes yes if

$$
f(b)>\beta x(s)+f(B), \text { i.e., if } \beta x(s)<p,
$$

and votes no otherwise. 
Similarly $S$ 's strategy is:

- If $L$ votes yes, $S$ votes yes if

$$
(1-\alpha) x(\bar{s})+f(b)>x(\bar{s})+f(b) \text {, i.e., if } \alpha x(\bar{s})<0,
$$

and votes no otherwise.

- If $L$ votes $n o, S$ votes yes if

$$
f(B)>(1-\beta) x(\bar{s})+f(B) \text {, i.e., if }(1-\beta) x(\bar{s})<0,
$$

and votes no otherwise.

Hence for all $s$, the manager will choose $\alpha=0, \beta=1$, to maximize the range of proposals that are rejected. ${ }^{23}$

2. Negative proposal: $p \in \mathcal{P}-$, i.e., $p<0$

- If $S$ votes yes, $L$ votes yes if

$$
\alpha x(s)+f(b) \geq f(B) \text {, i.e., if } \alpha x(s) \geq-p,
$$

and votes no otherwise.

- If $S$ votes no, $L$ votes yes if

$$
x(s)+f(b) \geq \beta x(s)+f(B) \text {, i.e., if }(1-\beta) x(s) \geq-p,
$$

and votes no otherwise.

Similarly $S$ 's strategy is:

- If $L$ votes yes, $S$ votes yes if

$$
(1-\alpha) x(\bar{s})+f(b) \geq f(b) \text {, i.e., if }(1-\alpha) x(\bar{s}) \geq 0,
$$

\footnotetext{
${ }^{23}$ Note that we always assume, here and in the rest of the paper, that when exactly indifferent between voting with management or against management, funds vote with management. This can be justified by using a "trembling hand" argument of the following form: when both funds vote identically, they assume that the firm's manager uses the strategy $\alpha=0, \beta=1$ with probability $1-\epsilon$, but with probability $\epsilon$ uses $\alpha=1, \beta=0$ instead, where $\epsilon$ is arbitrarily small. It is easy to see that this makes it strictly optimal for $S$ to always vote pro management. Alternatively, we could assume a small $\epsilon$ cost of voting anti management, which may arise, for example, from punishments by managers in affiliated firms.
} 
and votes no otherwise.

- If $L$ votes $n o, S$ votes yes if

$$
x(\bar{s})+f(B) \geq(1-\beta) x(\bar{s})+f(B), \text { i.e., if } \beta x(\bar{s}) \geq 0,
$$

and votes no otherwise.

Hence for all $s$, the manager will choose $\alpha=1, \beta=0$, to maximize the range of proposals that are accepted.

Proof of Proposition 2: For each proposal $p \in \mathcal{P}$, the fund announces a voting strategy, which requires it to calculate, for that proposal, the probability that it will face a client, i.e., the fund is an incumbent in that firm, vs a non-client, i.e., the fund is a challenger in that firm. Our assumptions earlier in the paper imply that the proposal arrival process is independent of the firm's relationship with any particular fund (and the ex ante allocation of funds is independent across firms). So for any proposal $p$, the fraction of clients $L$ encounters (on average) is exactly the fraction of clients $L$ has, $r^{L}$. Since there are only two funds, the fractions of clients $S$ encounters (on average for any proposal $p$ ) is $1-r^{L} .^{24}$

Consider an arbitrary proposal, $p$, where $p=f(b)-f(B)$, and for purposes of the proof we are going to deal only with positive, $p>0$, proposals (the extension for negative proposals follows exactly in the spirit of the proof of Proposition 1). Since each fund must commit to $K$-unconditional voting strategies, each will maximize its ex ante (expected) payoff from voting for or against each given proposal.

If $S$ votes yes, $L$ votes yes if

$$
\begin{gathered}
r^{L}(\alpha x+f(b))+\left(1-r^{L}\right)\left(\alpha x^{\prime}+f(b)\right)> \\
r^{L}(x+f(B))+\left(1-r^{L}\right)\left(x^{\prime}+f(B)\right)
\end{gathered}
$$

i.e., if $\alpha \bar{x}+\alpha f(B)>\bar{x}+f(b)$, where

$$
\bar{x}=r^{L} x+\left(1-r^{L}\right) x^{\prime} .
$$

\footnotetext{
${ }^{24}$ Let $s_{n}^{f} \in\{C, I\}$ be the state of fund $f \in\{L, S\}$ at firm $n$. If we have a discrete number of firms $n \in\{1, \ldots, N\}$ then

$$
r^{f}=\frac{1}{N} \sum_{i=1}^{N} \mathbb{I}\left(s_{i}^{f}=I\right),
$$

where $\mathbb{I}(\cdot)$ is the indicator function. While for a continuum of firms $n \in(0,1), r^{f}=\mathbb{P}\left(s_{n}^{f}=I\right)$, same for all $n$. In any case $r^{L}+r^{S}=1$.
} 
Thus, $L$ votes yes if $(1-\alpha) \bar{x}<p$.

If $S$ votes no, $L$ votes yes if

$$
f(b)>r^{L}(\beta x+f(B))+\left(1-r^{L}\right)\left(\beta x^{\prime}+f(B)\right),
$$

i.e., if $f(b)>\beta \bar{x}+f(B) \Rightarrow \beta \bar{x}<p$.

If $L$ votes yes, $S$ votes yes if

$$
\begin{gathered}
\left(1-r^{L}\right)((1-\alpha) x+f(b))+r^{L}\left((1-\alpha) x^{\prime}+f(b)\right)> \\
\left(1-r^{L}\right)(x+f(b))+r^{L}\left(x^{\prime}+f(b)\right),
\end{gathered}
$$

i.e., if $(1-\alpha) \hat{x}+f(b)>\hat{x}+f(b)$, where

$$
\hat{x}=\left(1-r^{L}\right) x+r^{L} x^{\prime},
$$

i.e., if $\alpha \hat{x}<0$.

Similarly, if $L$ votes $n o, S$ votes yes if $(1-\beta) \hat{x}<0$.

Hence, the manager will choose $\alpha=0, \beta=1$, to maximize the range of proposals that are rejected.

The above analysis guarantees that no fund has any incentives to deviate from its strategy for all firms in the cross-section. Let us then consider firm specific deviations. As it is clear from the disclosure case $L$, for example, would find it optimal, if there were no penalty, to vote no for clients and non-clients when $x>x^{\prime}>p$, no just for clients when $x>p>x^{\prime}$, and yes for both when $p>x>x^{\prime}$. Hence there are deviations that would allow the SEC to credibly accuse the fund for a violation of its fiduciary obligations; this is when the fund's voting strategy is not the same across firms for the same proposal $p\left(x>p>x^{\prime}\right)$. So the maximum average benefit $L$ can get by deviating is $x-x^{\prime}$. This is the lowest penalty the SEC has to impose for any identifiable violation. In response to this $L$ finds it optimal to stick to the aforementioned strategy of uniform voting. ${ }^{25}$

Proof of Proposition 3: It is useful to write the best response correspondence of $L$ and $S$ for general veto powers, $q_{L S}, q_{L^{\prime} S}$, and $q_{L S^{\prime}}$. As before the manager follows the following strategy

1. If $L$ votes yes and $S$ votes yes, retain (hire) $L$ with probability $\alpha$.

\footnotetext{
${ }^{25}$ Of course the above argument requires the existence of negative proposals, since otherwise the SEC would just require the funds to always vote yes, and punish it if it did not. It is exactly the fact that the SEC can not verify in court which proposals are positive and which are negative that drives this result.
} 
2. If $L$ votes yes and $S$ votes no, retain (hire) $L$ with probability 0 .

3. If $L$ votes no and $S$ votes yes, retain (hire) $L$ with probability 1 .

4. If $L$ votes $n o$ and $S$ votes no, retain (hire) $L$ with probability $\beta$.

Given these, and $p=f(b)-f(B), L$ 's strategy, if in state $s \in\{C, I\}$, and hence $S$ in state $\bar{s}$, is:

- If $S$ votes yes, $L$ votes yes if

$$
\begin{aligned}
\alpha x(s)+f(b) & >x(s)+q_{L S^{\prime}} f(B)+\left(1-q_{L S^{\prime}}\right) f(b) \Rightarrow \\
(1-\alpha) x(s) & <q_{L S^{\prime}} p
\end{aligned}
$$

and votes no otherwise.

- If $S$ votes no, $L$ votes yes if

$$
\begin{aligned}
q_{L^{\prime} S} f(B)+\left(1-q_{L^{\prime} S}\right) f(b) & >\beta x(s)+q_{L S} f(B)+\left(1-q_{L S}\right) f(b) \Rightarrow \\
\beta x(s) & <\left(q_{L S}-q_{L^{\prime} S}\right) p
\end{aligned}
$$

and votes no otherwise.

Similarly $S$ 's strategy is:

- If $L$ votes yes, $S$ votes yes if

$$
\begin{aligned}
(1-\alpha) x(\bar{s})+f(b) & >x(\bar{s})+q_{L^{\prime} S} f(B)+\left(1-q_{L^{\prime} S}\right) f(b) \Rightarrow \\
\alpha x(\bar{s}) & <q_{L^{\prime} S} p
\end{aligned}
$$

and votes no otherwise.

- If $L$ votes $n o, S$ votes yes if

$$
\begin{aligned}
q_{L S^{\prime}} f(B)+\left(1-q_{L S^{\prime}}\right) f(b) & >(1-\beta) x(\bar{s})+q_{L S} f(B)+\left(1-q_{L S}\right) f(b) \Rightarrow \\
(1-\beta) x(\bar{s}) & <\left(q_{L S}-q_{L S^{\prime}}\right) p
\end{aligned}
$$

and votes no otherwise.

Setting $q_{L^{\prime} S}=0$, it is clear that $S$ votes no for all $\alpha$ in $[0,1]$ given that $L$ votes yes. Hence, in this case to maximize the range of proposals for which $L$ votes no (or to minimize 
the range of proposals for which $L$ votes yes) the manager sets $\alpha=0$. Now regarding $\beta$ we compare the following two choices (we shall show at the conclusion of the proof that these are the only two possible values of $\beta$ we need to consider):

1. $\beta=1$. Then $S$ always votes yes if $L$ votes no. Regarding the choice of $L$ we have to consider the possible regions of the proposal

- For

$$
p \leq x(s) \frac{1}{q_{L S}}
$$

it is a weakly dominant strategy for $L$ to vote $n o$, to which $S$ responds by voting yes, resulting in probability of rejection of the proposal, $\mathbb{P}[n o]=q_{L S^{\prime}}$.

- For

$$
x(s) \frac{1}{q_{L S}}<p \leq x(s) \frac{1}{q_{L S^{\prime}}},
$$

there are two possible equilibria (in pure strategies): one in which $L$ votes yes, and $S$ votes no, which results to $\mathbb{P}[n o]=0$, and one in which $L$ votes no, and $S$ votes yes, with $\mathbb{P}[n o]=q_{L S^{\prime}}$.

- For

$$
p>x(s) \frac{1}{q_{L S^{\prime}}},
$$

it is a weakly dominant strategy for $L$ to vote yes, to which $S$ responds by voting no, which results to $\mathbb{P}[n o]=0$.

2. $\beta=\hat{\beta}(s)$, where

$$
\hat{\beta}(s)=\frac{x(\bar{s}) q_{L S}}{q_{L S}[x(s)+x(\bar{s})]-q_{L S^{\prime}} x(s)},
$$

and let

$$
\hat{p}(s)=\frac{x(s) x(\bar{s})}{q_{L S}[x(s)+x(\bar{s})]-q_{L S^{\prime}} x(s)} .
$$

Note that $\hat{\beta}(s)<1$ and $\hat{p}(s)<x(s) / q_{L S}<x(s) / q_{L S^{\prime}}$. Regarding the choices of both funds we have to consider the possible regions of the proposal

- For

$$
p \leq \hat{p}(s),
$$

it is a weakly dominant strategy for $L$ to vote $n o$, to which $S$ responds by voting no, resulting in probability of rejection of the proposal, $\mathbb{P}[n o]=q_{L S}$.

- For

$$
\hat{p}(s)<p \leq x(s) \frac{1}{q_{L S^{\prime}}},
$$


there are two possible equilibria (in pure strategies): one in which $L$ votes yes, and $S$ votes no, which results to $\mathbb{P}[n o]=0$, and one in which $L$ votes $n o$, and $S$ votes yes, with $\mathbb{P}[n o]=q_{L S^{\prime}}$.

- For

$$
p>x(s) \frac{1}{q_{L S^{\prime}}},
$$

it is a weakly dominant strategy for $L$ to vote yes, to which $S$ responds by voting no, which results to $\mathbb{P}[n o]=0$.

The manager wants to maximize $\mathbb{P}[n o]$ for each proposal $p$. For proposals such that $p<\hat{p}(s)<x(s) / q_{L S}$, the manager chooses $\beta=\hat{\beta}(s)<1$, since this induces unique equilibrium behaviour that leads to $\mathbb{P}[n o]=q_{L S}>q_{L S^{\prime}}$, which is better than the unique behaviour induced for proposals in this range by setting $\beta=1$. For proposals $\hat{p}(s)<p<x(s) / q_{L S}$ it is a best response for him to choose $\beta=1$ since this guarantees $\mathbb{P}[n o]=q_{L S^{\prime}}$, which is weakly larger than the corresponding probability under any equilibrium occurring for $\beta=\hat{\beta}(s)$ for proposals in this region. For proposals $p>x(s) / q_{L S}$ the choice of $\beta \in\{\hat{\beta}(s), 1\}$ is irrelevant to the behaviour of the funds, and so it is a weak best response for the firm's manager to choose $\beta=1$.

We conclude the proof by arguing that it is sufficient to consider $\beta \in\{\hat{\beta}(s), 1\}$. The firm's manager's goal is to get $L$ to vote $n o$, and if, in addition it is possible, to get $S$ also to vote $n o$. If $L$ votes no, we know that $S$ also votes $n o$ if and only if $p \leq \frac{(1-\beta) x(\bar{s})}{q_{L S}-q_{L S^{\prime}}}$. In order to induce $S$ to vote no over as wide a range of proposals as possible, the manager should aim to make $\beta$ small, but, unfortunately, that gets in the way of inducing $L$ to vote no, since if $S$ votes $n o, L$ votes no if and only if $p \leq \frac{\beta x(s)}{q_{L S}}$. Since the two relevant upper bounds are, respectively, decreasing and increasing in $\beta$, there is a unique $\beta$, defined by $\frac{(1-\beta) x(\bar{s})}{q_{L S}-q_{L S^{\prime}}}=\frac{\beta x(s)}{q_{L S}} \equiv \hat{p}(s)$ which guarantees that both funds vote no in equilibrium for $p \leq \hat{p}(s)$. Everywhere else, the manager cannot induce both funds to vote $n o$, and thus may as well choose (sometimes with indifference, as the proof above demonstrates) to set $\beta=1$.

Proof of Proposition 5: We proceed by backward induction.

At $t=T$ given $p_{T}=f\left(b_{T}\right)-f\left(B_{T}\right)$, let $L$ be in state $s$, and hence $S$ in state $\bar{s}$. If $S$ votes yes, $L$ votes yes if $\left(1-\alpha_{T}\right) x(s)<p_{T}$. If $S$ votes no, $L$ votes yes if $\beta_{T} x(s)<p_{T}$. If $L$ votes yes, $S$ votes yes if $\alpha_{T} x(\bar{s})<0$. If $L$ votes no, $S$ votes yes if $\left(1-\beta_{T}\right) x(\bar{s})<0$. Hence for all $s$, the manager will choose $\alpha_{T}=0, \beta_{T}=1$, to maximize the range of proposals that are rejected. Under this equilibrium, $S$ always votes no, and the manager gives the contract to $L$ if it votes no, and does not give it to $L$ if it votes yes.

At $t=T-1$ given $p_{T-1}=f\left(b_{T-1}\right)-f\left(B_{T-1}\right)$, let $L$ be in state $s$, and hence $S$ is in state $\bar{s}$. Assume for now that $p_{T}$ is known at $T-1$. Note that the vote of $S$ never affects the 
voting outcome. Then if $S$ votes yes, $L$ votes yes if

$$
\begin{gathered}
\alpha_{T-1} x(s)+f\left(b_{T-1}\right)+\alpha_{T-1} \delta \Pi_{T}^{L}\left(I ; p_{T}\right)+\left(1-\alpha_{T-1}\right) \delta \Pi_{T}^{L}\left(C ; p_{T}\right)>x(s)+f\left(B_{T-1}\right)+\delta \Pi_{T}^{L}\left(I ; p_{T}\right) \Rightarrow \\
\left(1-\alpha_{T-1}\right) x(s)<p_{T-1}+\left(1-\alpha_{T-1}\right) \delta\left[\Pi_{T}^{L}\left(C ; p_{T}\right)-\Pi_{T}^{L}\left(I ; p_{T}\right)\right] .
\end{gathered}
$$

If $S$ votes no, $L$ votes yes if

$$
\begin{aligned}
f\left(b_{T-1}\right)+\delta \Pi_{T}^{L}\left(C ; p_{T}\right) & >\beta_{T-1} x(s)+f\left(B_{T-1}\right)+\beta_{T-1} \delta \Pi_{T}^{L}\left(I ; p_{T}\right)+\left(1-\beta_{T-1}\right) \delta \Pi_{T}^{L}\left(C ; p_{T}\right) \Rightarrow \\
\beta_{T-1} x(s) & <p_{T-1}+\beta_{T-1} \delta\left[\Pi_{T}^{L}\left(C ; p^{\prime}\right)-\Pi_{T}^{L}\left(I ; p_{T}\right)\right] .
\end{aligned}
$$

If $L$ votes yes, $S$ votes yes if

$$
\begin{array}{r}
\left(1-\alpha_{T-1}\right) x(\bar{s})+f\left(b_{T-1}\right)+\left(1-\alpha_{T-1}\right) \delta \Pi_{T}^{S}\left(I ; p_{T}\right)+\alpha_{T-1} \delta \Pi_{T}^{S}\left(C ; p_{T}\right)> \\
x(\bar{s})+f\left(b_{T-1}\right)+\delta \Pi_{T}^{S}\left(I ; p_{T}\right) \Rightarrow \\
\alpha_{T-1} x(\bar{s})<\alpha_{T-1} \delta\left[\Pi_{T}^{S}\left(C ; p_{T}\right)-\Pi_{T}^{S}\left(I ; p_{T}\right)\right] .
\end{array}
$$

If $L$ votes no, $S$ votes yes if

$$
\begin{aligned}
f\left(B_{T-1}\right)+\delta \Pi_{T}^{S}\left(C ; p_{T}\right) & >\left(1-\beta_{T-1}\right) x(\bar{s})+f\left(B_{T-1}\right)+\left(1-\beta_{T-1}\right) \delta \Pi_{T}^{S}\left(I ; p^{\prime}\right)+\beta_{T-1} \delta \Pi_{T}^{S}\left(C ; p_{T}\right) \Rightarrow \\
\left(1-\beta_{T-1}\right) x(\bar{s}) & <\left(1-\beta_{T-1}\right) \delta\left[\Pi_{T}^{S}\left(C ; p_{T}\right)-\Pi_{T}^{S}\left(I ; p_{T}\right)\right]
\end{aligned}
$$

where $\Pi_{t}^{f}(s ; p)$ is the $t$ period continuation payoff of fund $f \in\{L, S\}$, when it enters that period in state $s \in\{C, I\}$, and the proposal at that period is $p$.

Observe that under the $\alpha_{T}=0, \beta_{T}=1$ equilibrium at $T$ the small fund always votes no either it is in state $C$ or $I$. Now for the large fund we have the following cases:

(i) If $x<p_{T}$ then $x^{\prime}<p_{T}$ also, so $L$ votes yes regardless its state and gets $f\left(b_{T}\right)$. So $S$ will get the contract and has payoff $x(\bar{s})+f\left(b_{T}\right)$ at state $\bar{s}$ so that in this case $\Pi_{T}^{L}\left(C ; p_{T}\right)=\Pi_{T}^{L}\left(I ; p_{T}\right)$, and $\Pi_{T}^{S}\left(C ; p_{T}\right)<\Pi_{T}^{S}\left(I ; p_{T}\right)$.

(ii) If $x^{\prime}<p_{T}<x, L$ votes yes if it is in state $C$, and does not get the contract and has payoff $f\left(b_{T}\right)$; while $L$ votes $n o$ if it is in state $I$, and gets the contract and has payoff $x+f\left(B_{T}\right)>f\left(b_{T}\right)=p_{T}+f\left(B_{T}\right)$. So $S$ will get the contract and have payoff $x+f\left(b_{T}\right)$ if it is in state $I$, while will not get the contract and have payoff $f\left(B_{T}\right)$ if it is in state $C$. So that in this case $\Pi_{T}^{L}\left(C ; p_{T}\right)<\Pi_{T}^{L}\left(I ; p_{T}\right)$, and $\Pi_{T}^{S}\left(C ; p_{T}\right)<\Pi_{T}^{S}\left(I ; p_{T}\right)$.

(iii) If $x^{\prime}>p_{T}$ then $x>p_{T}$ also, so $L$ votes no regardless its state $s$ and gets $x(s)+f\left(B_{T}\right)$. So $S$ will never get the contract and has payoff $f\left(B_{T}\right)$ so that in this case $\Pi_{T}^{L}\left(C ; p_{T}\right)<$ $\Pi_{T}^{L}\left(I ; p_{T}\right)$, and $\Pi_{T}^{S}\left(C ; p_{T}\right)=\Pi_{T}^{S}\left(I ; p_{T}\right)$. 
Now given that

$$
\begin{aligned}
& \Pi_{T}^{L}\left(C ; p_{T}\right) \leq \Pi_{T}^{L}\left(I ; p_{T}\right) \\
& \Pi_{T}^{S}\left(C ; p_{T}\right) \leq \Pi_{T}^{S}\left(I ; p_{T}\right)
\end{aligned}
$$

for all $p_{T}$ we have that $\alpha_{T-1}=0, \beta_{T-1}=1$ is the equilibrium.

Observe that if in cases (i)-(iii) above we substitute $T$ for $T-1, f\left(b_{T}\right)$ by $f\left(b_{T-1}\right)+$ $\delta \Pi_{T}^{L}\left(C ; p_{T}\right), f\left(B_{T}\right)$ by $f\left(B_{T-1}\right)+\delta \Pi_{T}^{L}\left(I ; p_{T}\right)$, and so $p_{T}$ by $p_{T-1}+\delta\left[\Pi_{T}^{L}\left(C ; p_{T}\right)-\Pi_{T}^{L}\left(I ; p_{T}\right)\right]$, we can show that

$$
\begin{aligned}
\Pi_{T-1}^{L}\left(C ; p_{T-1}\right) & \leq \Pi_{T-1}^{L}\left(I ; p_{T-1}\right), \\
\Pi_{T-1}^{S}\left(C ; p_{T-1}\right) & \leq \Pi_{T-1}^{S}\left(I ; p_{T-1}\right),
\end{aligned}
$$

for all $p_{T-1} \in \mathcal{P}$. Then we can repeat the same steps as in the beginning of the proof for $T-2$, with trivial changes of notation, and get that $\alpha_{T-2}=0, \beta_{T-2}=1$ and so on.

Furthermore since inequalities (1) and (2) hold for all $p_{T} \in \mathcal{P}$, it is not necessary that the exact value of $p_{T}$ is known at $T-1$ and so instead of $\Pi_{T}^{f}\left(s ; p_{T}\right)$ we could have

$$
\Pi_{T}^{f}(s)=\sum_{i=1}^{K} \pi^{i} \Pi_{T}^{f}\left(s, p^{i}\right),
$$

for $f \in\{L, S\}$ and $s \in\{C, I\}$, and all the statements we made above are still valid. Similarly for all $t<T$.

Proof of Proposition 6: Let

$$
\tilde{x}(r)=r x+(1-r) x^{\prime}
$$

clearly increasing in $r$. Since the probability of a proposal arriving is independent and identical across firms we can view the problem per proposal $p \in \mathcal{P}$. The relevant state per period $t \in\{1, \ldots, T\}$ is the fraction of firms in which fund $f \in\{S, L\}$ has the pensions contract, let $r_{t}^{f}$ (so the fraction of contracts of the other fund is $1-r_{t}^{f}$ ). Since proposals are independent of which fund holds the pensions contract, when a fund $f$ announces its voting policy at the beginning of each $t$ the fraction of clients it anticipates to face for each proposal is exactly $r_{t}^{f}$.

At $T$ we know that managers across firms will follow the symmetric strategy $a_{T}=0, \beta_{T}=$ 1 ; under this $S$ will vote no for all proposals, while $L$ will vote no for proposals $p$ such that $\tilde{x}\left(r_{T}^{L}\right)>p$ and votes yes otherwise. Then for a large enough number of firms $N$ the 
expectation at the beginning of $T$ (before any proposals have been observed) of the fraction of contracts $L$ holds at the end of $T$ is

$$
\sum_{i=1}^{K} \pi^{i} \mathbb{I}\left(\tilde{x}\left(r_{T}^{L}\right)>p^{i}\right) .
$$

The problem at $T-1$ is very similar to the one in the case of no disclosure. The solution there boiled down to proving that the (expected) continuation payoff of a fund is larger if it enters the next period as an incumbent in a firm rather than as a challenger, which in turn relies on the fact that $x>x^{\prime}$. Hence to prove the optimality of the symmetric equilibrium $a_{T-1}=0, \beta_{T-1}=1$ in the case of disclosure, we must show that the (expected) continuation payoff of a fund is larger if conditional on a proposal it gets retained (hired) rather than fired (not hired). ${ }^{26}$ But this is true since being retained (hired) for proposal $p^{i}$ at $T-1$ would increase one's expectation over the fraction of contracts it holds at $T$ by $\pi^{i}$ ceteris paribus; since the continuation payoff is linear in $\tilde{x}(r)$, and $\tilde{x}(r)$ is linear and increasing in $r$ this guarantees the required ranking. Similarly for all $t<T-1$.

\section{References}

Admati, A. R., P. Pfleiderer, and J. Zechner, 1994, "Large Shareholder Activism, Risk Sharing, and Financial Market Equilibrium," Journal of Political Economy, 102, 1097-1130.

Ashraf, R., and N. Jayaraman, 2007, "Institutional Investors' Trading Behavior in Mergers and Acquisitions," SSRN eLibrary.

Black, B., 1990, "Shareholder Passivity Reexamined," Michigan Law Review, 89, 520-608.

Brickley, J. A., R. C. Lease, and C. W. Smith-Jr., 1988, "Ownership structure and voting on antitakeover amendments," Journal of Financial Economics, 20, 267 - 291.

Choi, S. J., J. E. Fisch, and M. Kahan, 2010, "The Power of Proxy Advisors: Myth or Reality?," Emory Law Journal, 59, 869-918.

Cohen, L., and B. Schmidt, 2009, "Attracting Flows by Attracting Big Clients," Journal of Finance, 64, 2125-2151.

Cremers, M., and R. Romano, 2009, "Institutional Investors and Proxy Voting: The Impact of the 2003 Mutual Fund Voting Disclosure Regulation," Working Paper.

\footnotetext{
${ }^{26}$ Note that from the very definition of disclosure the same outcome will realize for client and non-client firms facing the same proposal
} 
Dasgupta, A., and G. Piacentino, 2011, "The Wall Street Walk when Blockholders Compete for Flows," SSRN eLibrary.

Dasgupta, A., and A. Prat, 2008, "Information Aggregation in Financial Markets with Career Concerns," Journal of Economic Theory, 143, 83-113.

Davis, G., and E. H. Kim, 2007, "Business ties and proxy voting by mutual funds," Journal of Financial Economics, 85, 552-570.

Davis, G. F., and M. Yoo, 2003, "The Shrinking World of the Large American Corporation: Common Ownership and Board Ties, 1990-2001," Gerer et Comprendre, 74, 51-62.

Duan, Y., E. S. Hotchkiss, and Y. Jiao, 2011, "Business Ties and Information Advantage: Evidence from Mutual Fund Trading," SSRN eLibrary.

Gillan, S., and L. Starks, 2007, "The Evolution of Shareholder Activism in the United States," Journal of Applied Corporate Finance, 19, 55-73.

Grossman, S., and O. Hart, 1980, "Takeover Bds, the Free Rider Problem, and the Theoryof the Corporation," Bell Journal of Economics, 11, 42-64.

Holmstrom, B., and J. Tirole, 1997, "Financial Intermediation, Loanable Funds, and The Real Sector," Quarterly Journal of Economics, 112, 663-691.

Matvos, G., and M. Ostrovsky, 2010, "Heterogeneity and peer effects in mutual fund proxy voting," Journal of Financial Economics, 98, 90 - 112.

McCahery, J. A., L. T. Starks, and Z. Sautner, 2010, "Behind the Scenes: The Corporate Governance Preferences of Institutional Investors," SSRN eLibrary.

Pound, J., 1988, "Proxy contests and the efficiency of shareholder oversight," Journal of Financial Economics, 20, 237 - 265.

SEC, 2003, "Disclosure of Proxy Voting Policies and Proxy Voting Records by Registered Management Investment Companies," 17 CFR Parts 239, 249, 270, and 274 Release Nos. 33-8188, 34-47304, IC-25922.

Shleifer, A., and R. Vishny, 1986, "Large Shareholders and Corporate Control," Journal of Political Economy, 94, 461-48.

Vayanos, D., and P. Woolley, 2009, "An Institutional Theory of Momentum and Reversal," LSE working paper. 
Walker, D., 2009, "A Review of Corporate Governance in UK Banks and Other Financial Industry Entities - Final Recommendations," H M Treasury, United Kingdom. 